\title{
REGALO PARA UNA MADRE: UNA MUCHACHA ESCLAVA MUSULMANA DEL NIETO DE ABU ZAYD, EL SEÑOR DE BORRIOL (1301)
}

Por

ROBERT I. BURNS, S.J.

La venta de esclavos musulmanes en la Valencia cruzada ha dejado bastantes vestigios documentales; sin embargo, los contratos de regalo - aparte de testamentos- raramente han perdurado. Tales regalos eran usuales, a juzgar por el ejemplo del rey Jaime el Conquistador, que otorgaba cautivos y cautivas musulmanes por miles a gobernadores, prelados, y barones predilectos (1). La carta de regalo que se incluye merece consideración como ejemplo de tales transferencias de propiedad humana en las primeras generaciones que siguieron a la conquista, una época apenas documentada en sus aspectos sociales.

Los principales que aparecen en el contrato nos proporcionan un interés suplementario. El donante era Pedro Eximénez (Pere Ximèn o Eiximenis), señor de Borriol; el beneficiario era su madre Oria (en catalán Oria) Eiximenis (2). Se trata de la célebre familia valenciana de Arenós, fundada por el caballero aragonés Eximeno Pérez de Tarazona, hermano del Justicia de Aragón, y alto funcionario en la corte del rey Jaime. Eximeno recibió en 1242 la baronía de Arenós, al noroeste de Castellón en la región de Alt Millars. Además, recibió en 1254 la ciudad y castillo de Borriol, bastante lejos al sur de ambas regiones. Después de eso él y su familia más próxima cambiaron el título Arenós, por el de Tarazona. Eximeno sirvió como lugarteniente o virrey de Valen-

(1) Ramón Muntaner, Crònica, cap. 13, en Les quatre grans cróniques, ed. Ferrán Soldevilla (Barcelona: 1983).

(2) Uso formas aragonesas/castellanizadas para los nombres que aquí aparecen en deferencia a su origen familiar, con variantes catalanas en ocasiones entre paréntesis, y nombres catalanes para los de persona no familiares. 
cia en 1240, y murió poco después de participar en la cruzada real a Murcia en 1266 .

Eximeno se había casado con Alda, hija del converso último wãli de Valencia Abú Zayd y de su esposa cristiana María Fernández. (La baronía de Arenós parece haber sido la dote aportada por Alda y confirmada por el rey por los servicios que Eximeno había prestado).

La propia hija de Eximeno, Teresa, casó con el hijo cristiano de Abū Zayd Fernando (Ferrán). Eximeno y Alda tuvieron al menos dos hijos, Blasco Eximenez (Blai Eiximenis $d^{\prime}$ ) de Arenós, y Eximeno (Eiximèn d') de Arenós, de cuyas actividades se da cuenta a lo largo de la primera década del siglo XIV. Este Eximeno de Arenós tuvo sucesivamente tres hijos; Gonzalbo Eximenez de Arenós, Fernando Eximenez de Arenós, y Eximeno Pérez de Arenós. Estos y otros miembros del clan Arenós continuaron desempeñando un papel distinguido en la historia de Valencia y de la Corona de Aragón a lo largo de varias generaciones.

¿Dónde en el seno de la familia podría incluirse el Pedro Eximenez de nuestra carta? Parece tratarse del Eximeno Pérez que aparece justo al final de la lista de arriba. Unos documentos de los archivos de la Catedral de Valencia muestran un Pedro Eximenez como señor de Borriol en 1303, cuya hija Francesca añadía una cláusula a su testamento; luego a Eximeno como señor de Borriol en 1307; y finalmente en 1346 a Eximeno Pérez como el difunto señor de Borriol y a su viuda Francesca (3). A pesar de las variantes del nombre, este Pedro Eximenez, Eximeno, y Eximeno Pedro o Pérez parecen ser todos ellos el Pedro Eximenez de nuestra carta. Aunque las figuras públicas más famosas de la familia Arenós se destacan en la historia, el completo árbol genealógico necesita todavía clarificación en base a los manuscritos; nuestro Pedro Eximenez y su madre Oria pueden contribuir a esta causa.

El señor de Borriol decidió hacer este regalo «en base a los muchos apropiados y gratos servicios» que su madre le había proporcionado, y que le seguía proporcionando día a día. En presencia de ella le traspasó «para siempre, cierta sarracena blanca de mi propiedad llamada Cozeys». Aunque pueda hacernos recordar nombres femeninos como Khassah o un diminutivo de ${ }^{c} \bar{A}-$ 'išsa como Sū̌āa con una suave c latina en la carta, investigaciones posteriores nos revelan un más apropiado Qudays («Santo»), puesto en masculino, como no era raro en la época (4). El resto del documento acumula las fórmulas usuales de Derecho Romano para hacer el regalo incondicional, total, e irrevocable, renunciando a todos los derechos para reintepretar, hacer deman-

(3) Elias Olmos Canalda, Pergaminos de la catedral de Valencia (Valencia: 1961), doc. 977 (19 de Septiembre de 1303), "Pedro Eximent"; docs. 2244 y 2247 (28 de febrero de 1346), Eximen Pérez. Estas notas de catálogo han de ser contrastadas con los manuscritos.

(4) Véase el estudio de Ana Labarta sobre 'A'iša y sus diminutivos romances y árabes, en La onomástica de los moriscos valencianos (Madrid: 1987), pp. 54-55. Debo a Paul Chevedden el haber encontrado Qudays. 
das o buscar escapatorias a la Ley. Son instructivas todas estas elaboraciones técnicas para un texto tan prosaico.

Pedro Eximenez firmó el documento al final; Oria no lo hizo, a pesar de su presencia en persona y de su participación. Los testigos eran dos, Pere Bianya (un valle del río Garrotxa), pañero o comerciante en paños, y Bertrán (Beltrán) Gil de Loarre, ambos "ciudadanos de Valencia". El "notario público de Valencia" , el cual "redactó y completo" la carta, fue Pere Ferrer. Por supuesto la esclava no desempeñaba más papel que el de cualquier otra propiedad.

\section{(Traducido por Ovidio Carbonell)}

Archivo Histórico Nacional

Valencia

Clero: Valencia, Franciscanas: carpeta 3281, doc. 15

Noverint universi quod ego Petrus Eximini dominus de Burriol, propter multa grata et idonea servicia que vos dompna Oria Eximini mater mea mihi fecistis et cotidie continuo [?] ${ }^{5}$ facere non cessatis, dono et concedo vobis prenominate matri mee, presenti et recipienti et vestris, perpetuo quandam Sarracenam meam albam vocatam Cozeys.

Hanc autem donacionem dicte Sarracene facio vobis et vestris perpetuo pure, deliberate, et sine aliqua retencione, vinculo, et condicione, prout melius, plenius, sanius, ac utilius potest dici, scribi, et intelligi ad commodum et salvamentum vestri et vestrorum, perpetuo.

Ita quod de cetero vos et vestri habeatis ipsam Sarracenam ad omnes vestras voluntates omnimodo faciendas. Promittentes vobis bona fide quod numquam contra hanc donacionem veniam, nec aliquem venire faciam seu permittam. Immo ipsam ratam et firmam habere promitto et semper inviolabiliter observare.

Et ex certa scientia, renuncio super hiis omni iuri omnique foro contra predicta venientibus.

Quod est actum Valencie, nonas lulii, anno domini MCCC primo.

Sig + num Petri Eximini predicti qui hoc concedo et firmo.

Testes huius rei sunt: Petrus Bianya draperius, et Bertrandus Egidii de Loarre, cives Valencie.

Sig + num Petri Ferrarii, notarii publici Valencie, qui hoc scripsit et clausit.

(5) ¿Comunitati? 